\title{
Update on Forelock Approach of Hair Transplantation
}

\section{Michael L. Beehner, MD Saratoga Springs, New York}

\section{Rationale for Using a "Forelock Approach"}

It's been almost 14 years since I sat in that lecture room in San Antonio at the American Hair Loss Council's annual meeting and heard Manny Marritt talk for almost an hour and a half on the concept of using a centralized forelock approach. Several hundred patients later, I can assure you that it is an approach that will bail you out with many a young and very bald patient. It enables you to offer something and to significantly help that person in front of you. present in these selected patients, one has to narrow attention to limited areas, and the one area that must necessarily be totally deemphasized is the vertex. Some comments will be made later as to possible cosmetic approaches here. In addition, another area that is deemphasized or totally left out is the fronto-temporal recession on each side. This area should never be aggressively filled in a man in his early or mid-20s, in my opinion.

Fourth, in creating these lateral "mirror image" zones, it
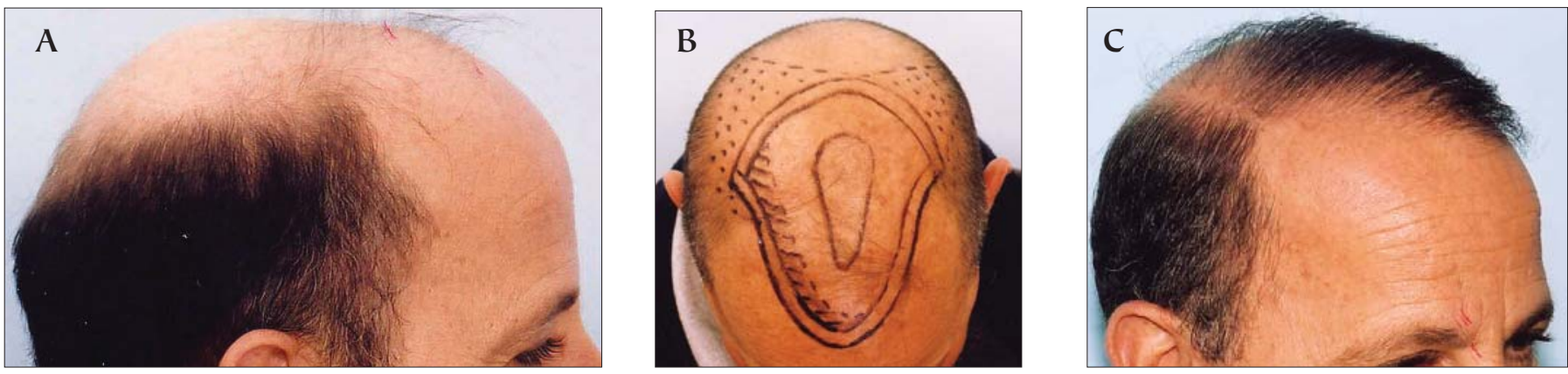

Figure 1. A: Norwood VII 50-year-old male before HT; B: shield pattern drawn on scalp; C: after 3 sessions of 1,200 each

The rationale for using a "frontal forelock" approach as the "last resort" in the challenging hair transplant patient is based on a number of things. Very importantly, this approach actually works only because there are a lot of men who lose their hair in exactly this manner and at some point are seen to possess this precise pattern of hair loss-one that preserves a swath of hair in the front-central portion of their scalp, while the areas to the side and behind thin and go bald. I recently did a review of both all the consultations and all of the surgeries performed in our practice over the past 4 years and found that $15 \%$ of both groups received either a recommendation for or the actual performing of a forelock surgery.

The most common reason that many of our male patients present to us is because they are losing the "framing" of their face. They look in the mirror and they see the youthful, full-haired look giving way to a "see-through," diminishing thatch of hair in front. The forelock addresses and satisfies the restoration of this impending loss.

Second, a "forelock" pattern is used when there is presently, or possibly will be in the future, a disproportion between the available "safe" donor hair and the needs for hair to fill in the projected alopecic scalp area. With the forelock approach, one is able to make "less" appear to be "more." All of the outlying sparser zones play off of the central density of the forelock's "core" and thus appear fuller to the observer. A "mirror image" approach is used in the lateral areas on both sides of the forelock body, in such a way that the decreasing gradient of density of the forelock body mirrors the decreasing density of the lateral fringe in its superior aspect. Often this is accomplished by augmenting the fringe "hump," if donor supplies allow, thus creating a blurred visual continuity of the forelock body and the surrounding fringe. In this way, the surgeon avoids leaving a shiny, bald alley of scalp between them.

Third, because of the "scarcity" element that is inherently is usually necessary to fill in what I term "scatter zones," areas of somewhat sparse FU density, which are usually located lateral and/or posterior to the forelock, its density being sparsest along the "crease" line and becoming somewhat denser as the fringe or the forelock body are approached in either direction. In Figures 1 B, 4A, and 5B, these are seen as seen to be filled in with dark dots. In the rear side zones of the forelock pattern, these scatter zones comprise the two "posterior parietal triangle" zones, which are the portions of the midscalp that are not on a horizontal plane (see Diagram A). The plane of these two triangular zones start to "tip" vertically to the side and rear. From a rear view this creates what I call a "paradox of curves." One sees the stronger convex contour of the forelock body, but at the same time can appreciate a concave contour to the rear border of the "scatter zone."

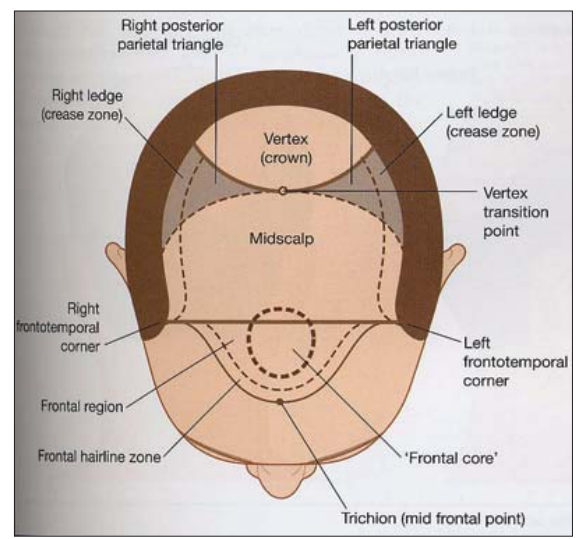

Zones and subzones of the alopecic scalp (from Haber-Stough text, Hair Transplantation)

Fourth, in using a "forelock" approach, the hair surgeon must creatively use gradients of density. There are only four ways I know of to create a gradient of density between two areas:

1. Vary the size of the grafts (i.e., number of hairs per graft) 


\section{Forelock Approach}

continued from page 11

2. Vary the planting density of the grafts (probably the most important means available)

3. Vary the caliber of hair (probably more theoretical than practical)

4. Selectively transplant in one zone at a given session and omit transplanting an adjacent zone

The last important reason for using a "forelock" approach, especially in the younger patient, is to protect that patient from looking bizarre or abnormal at some future time in his life due to unforeseen progression of his alopecia.

\section{Who Is a Candidate for a Forelock Pattern?}

There are basically only five types of candidates, and $98 \%$ of them are from the first two groups:

1. Too bald. This is the man of any age in whom the area of obviously balding scalp greatly exceeds the available "safe" donor hair. In general, most men with a bi-parietal width of over $14 \mathrm{~cm}$ can be put in this category. The younger the patient, the more I will lean towards $12 \mathrm{~cm}$ as my cutoff width, while on the other hand, I may rarely push it to $15 \mathrm{~cm}$ in a man of more mature age who possesses a reasonable amount of donor hair. The patient in Figure $1 \mathrm{~A}$ is a good example. His bald area is $18 \mathrm{~cm}$ wide and he received 3 sessions of transplants in the "shield" zone (Figure 1B), framing his face as you see in Figure 1C. Some may recall him as the patient we presented at the "Doctors \& Their Patients" session in Sydney.

2. Too young. In recent years, 22-23 years of age has become my unofficial cutoff age for transplanting young men. I use a "forelock" type of pattern, very often the more conservative "oval" one, in anyone in their early or mid20 s, or even up to the early 30 s, if I see warning signs for later severe alopecia, such as a family history of Norwood VII male relatives, presence $\begin{aligned} & \text { Figure 2. Oval forelock pattern on 22-year-old } \\ & \text { male }\end{aligned}$ of "whisker hair" around the ears, indistinct fringe, or the presence of significant miniaturization in the upper fringe zone. Figure 2 shows a 22 year old who we transplanted a few weeks ago using a conservative oval design and limiting MFUs to the front half of the forelock body, due to the dark, coarse nature of his hair.

To demonstrate how this approach fares over a period of time, Figures $3 \mathrm{~A}$ and $3 \mathrm{~B}$ show a young man who came to me in 1995 and had 3 forelock sessions of 750 grafts each. Figure 3B shows the side mirror-image appearance of the forelock hair 10 years later in 2005 . Without the surgery, he now would have Norwood VI baldness.

3. "Corrective" patient. In a patient in whom donor reserves are nearly depleted and large grafts are scattered all over the scalp, I try to remove the outlying grafts and consolidate them into a front-central area, with gradients going away from this denser central area. Usually the old grafts that are centrally located can be left in and the spaces between them simply filled in.

4. Patient specifically requests forelock pattern. I've had 3 patients over the years who specifically asked for only a small front-central forelock, and who otherwise would have been wonderful candidates for a full filled-in transplant, but did not want that much hair added. A small oval forelock is created along with a small "scatter zone" off to each side. Figures $4 A$ and $B$ show the results after 2 sessions for a man who made this request.

5. Patient with limited finances. If a patient is limited in financial resources, an easy and inexpensive way to frame his face is to transplant a small oval forelock as described above. Such a project requires very little hair and can be done at modest expense for the patient, often with only one session.

\section{Designing the Pattern and Performing the Surgery}

\section{Oval or Shield Pattern?}

After years of experimenting with various patterns, these two are the only ones I use now. I no longer use the "rounded arrowhead" pattern, because it looks too unnatural if it becomes separated from the temporal fringe.

I usually try to use the "shield" pattern whenever possible, which works out to around $70 \%$ of my forelock patients. If the amount of donor hair is really limited or unpredictable into the future, I tend to use the "oval" pattern, because the denser, central portion of the forelock is geometrically smaller than in the "shield" pattern. If the patient has a vertical facies and narrow top of the head, I lean toward the oval pattern also. As stated, the oval pattern is particularly valuable in the extremely young male, as I consider it to be the safest plan should he go on to later experience marked progression of his alopecia. If the patient plans to style his hair from one side to the other, I will try to use a "shield" pattern if possible. Put simply, of the two patterns, the "shield" pattern looks more like a full head of hair when the patient is viewed from the front or oblique angles.

\section{Oval Forelock Design Pattern}

In creating a conservative oval forelock design in the young male, I most commonly place the hairline height $7.5-8 \mathrm{~cm}$ above the supra-eyebrow line $(8.5-9 \mathrm{~cm}$ above the glabella) and draw in a small arc there. I then mark where the epicanthal line extends back near the upper fringe on each side. I then place a mid-line mark between these two points, projecting it back from the nose viewed tangentially. I then determine that the two side dots are equidistant and symmetrical. I next measure medially in from these two side points, around 1 or $1.5 \mathrm{~cm}$, and draw marks there, which will then be the lateral limit of the oval design. The last reference point I make is a dot at the vertex transition point (VTP), which is the point on the rear mid-scalp where the contour of the scalp begins to descend. Next, starting at the front hairline mark, I make a gracefully curved oval outline extending from the small arc in front to the two side points, and then back to the VTP in the rear. I then draw a curved dotted line off of the forelock, heading posteriorly and down toward the temporal fringe, behind which I create my sparse "scatter zone" of FUs, which 
help visually connect the forelock body to the side fringe hair. It is important that this be kept far back in the recession and not anteriorly. In the rear, another curved dotted line is drawn, which extends off of the rear forelock, curving down to the side fringe. This also is kept somewhat anterior and does not

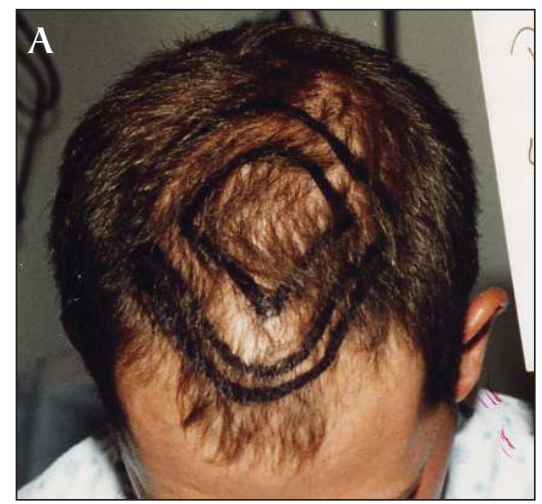

Figure 3. A: Shield pattern drawn in 1995 on 19-year-old male; B: same patient 10 years later, note "mirror image" effect laterally

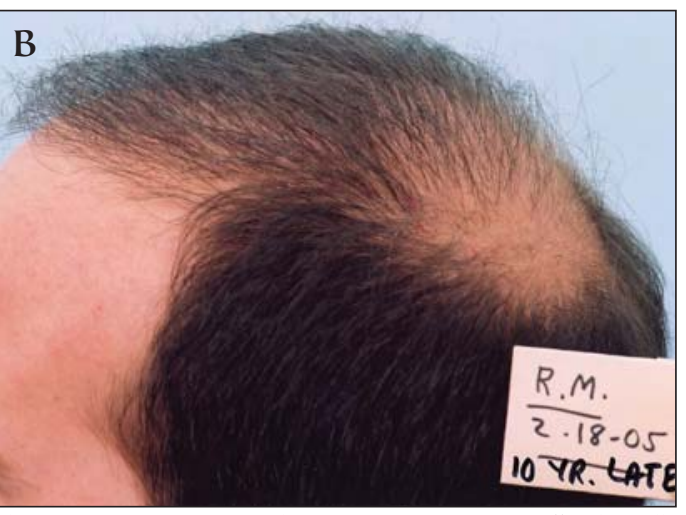

p a tie n t s and even in some of the Norwood VII ones. Its biggest attribute is that it creates a longer, fuller appearing frontal hairline, and the mirror image on either side brings the strong aspect of the forelock closer to the strong part of the fringe contour. As I noted, it looks fuller, but does require a little more donor hair than the oval pattern needs.

I create the initial landmark spots as I do with the oval forelock. The contour of the "shield's" front hairline is flared very gently in its lateral aspect and terminates at a point either in line with the epi-canthal line or, more commonly, just $1 \mathrm{~cm}$ lateral to it. This wider end point allows for a little bit fuller projection of the frontal hair and prevents it from

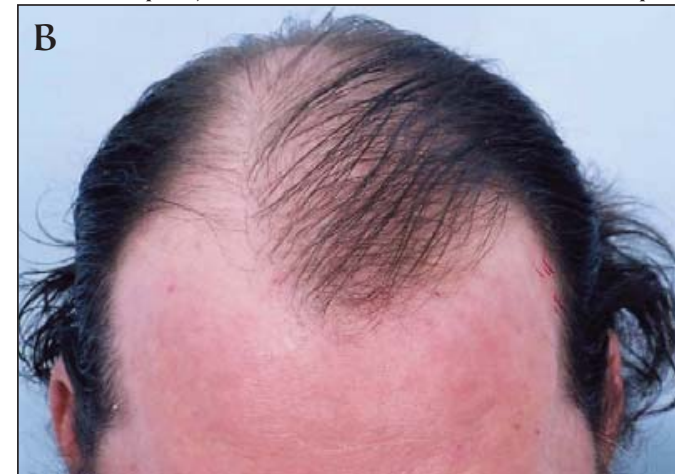

Figure 4. A: Limited size oval forelock drawn on 38-year-old male; B: results after 2 small sessions looking like a narrow frontal tuft. In the y o u n g e patient in his 20 s, I do limit the front hairline within the confines of the two epi-canthal line projections. The rear of this forelock design is the vertex transition point. The lines marking the rear borders of the scatter zones in back, in contrast with the oval forelock, come directly off of the VTP and thus create larger side "scatter zones" than are made with the oval forelock.

To show an example of the numbers and types of grafts I would use in a typical "shield" forelock session, the patient in Figure 5 (A and $\mathrm{B}$ ) received 380 FUs (1-, 2-, and 3-hair ones) along the front hair line zone, $380 \times 1.3 \mathrm{~mm} 4-6$ hair MFUs in the large central zone, 200 FUs in the rear border zone, and 200 FUs in each posterior parietal triangle "scatter zone." Most thinner areas and the 3-hair FUs in the denser areas.

I think the best way to style the oval forelock pattern of hair is to sweep it back toward one of the rear corners, usually the right side. This is more difficult with extremely coarse, wavy hair. For these patients I would recommend using a short, layered styling pattern.

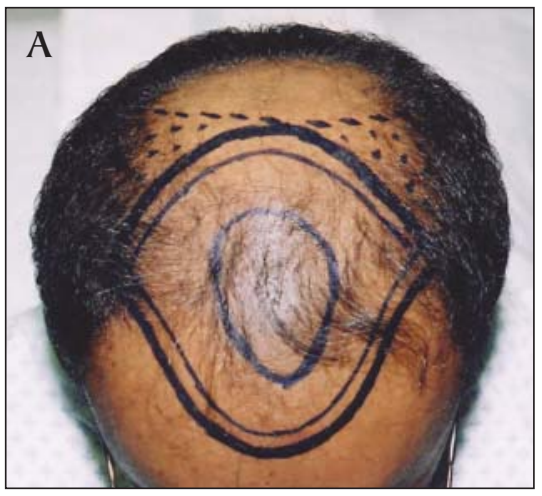

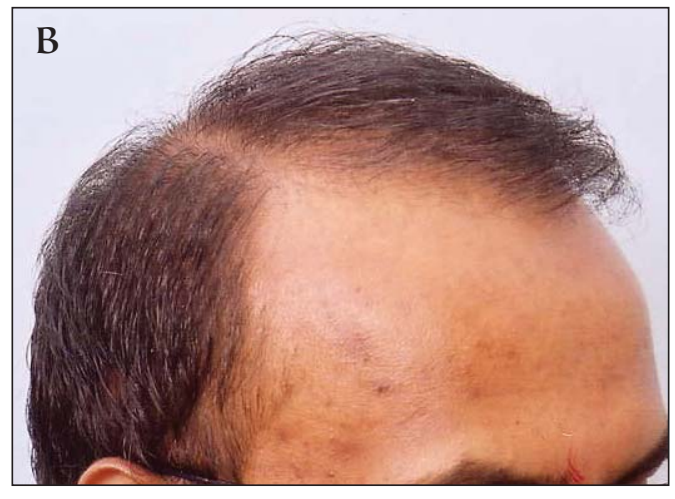

Figure 5. A: 34-year-old Norwood VI/VII pattern; B: after 2 sessions of 1,200 each patients require 2 or 3 sessions to achieve our cos m e tic goals. The timing and number of sessions depend often on how much residual "na- 


\section{Forelock Approach}

continued from page 13

tive" hair exists on top and whether the patient is willing to take finasteride. Sessions are usually a minimum of a year apart, so that I can "paint a picture" gradually, seeing what I accomplished in the previous session before adding to it. Often times, a single session can transform a patient's looks (Figures 6A and $6 \mathrm{~B}$; one session 11 months later), and some patients elect to stop at that point.

\section{Later Design \\ Considerations}

If the patient is over 50 and expresses a firm intention of styling his hair from the left to the right, one can use the "shield" pattern and "cheat" a little bit by loading up the left side and lateral hump a little more than the right side, thus creating a little more semblance of a "part" on that side.

Also, I always tell patients receiving a forelock pattern that 2 sessions have to be done on top before we can even consider putting some scattered Fus into the vertex. I am willing to scatter 600-1,200 FUs into a large vertex whorl zone after 2 or 3 sessions have been completed on top, provided there is sufficient donor hair and the patient's age makes it unlikely that his present pattern of alopecia will progress much.
Another more modest approach to the vertex is to simply place some "tacking hairs" in that portion of the vertex to which the patient styles or directs his forelock hair. Most often this is in the rear right vertex. Such hairs should be directed in the direction that the whorl would go and should be sparse and of the 1-to 2-hair variety, with no 3- or 4-hair FUs used. For patients with gray hair, these appear very natural and assist in holding their

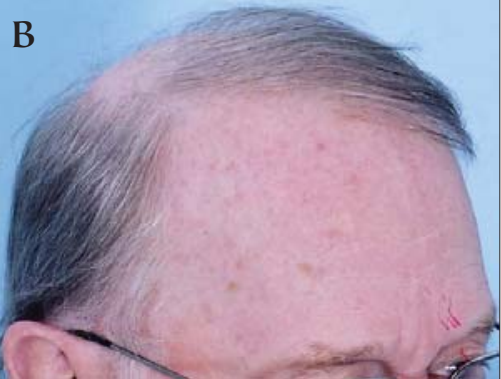
swept back hair in place.

\section{Conclusion}

I believe all hair surgeons should have the ability to take their present modus operandi of transplanting and be able to create a limited forelock type of transplant result for those patients in whom it is indicated. These designs, particularly the small to medium size oval forelock, can be used in virtually everybody, no matter how severe their hair loss. In some instances, it may have to be somewhat sparse looking in order to look natural. Having this pattern to use, the only patients I turn down for surgery are those with unrealistic expectations and those with psychiatric or medical contraindications. Using the forelock requires imagination and artistry, but brings the hair surgeon great satisfaction when one sees a patient return and you realize how much you have accomplished with so little. $\diamond$

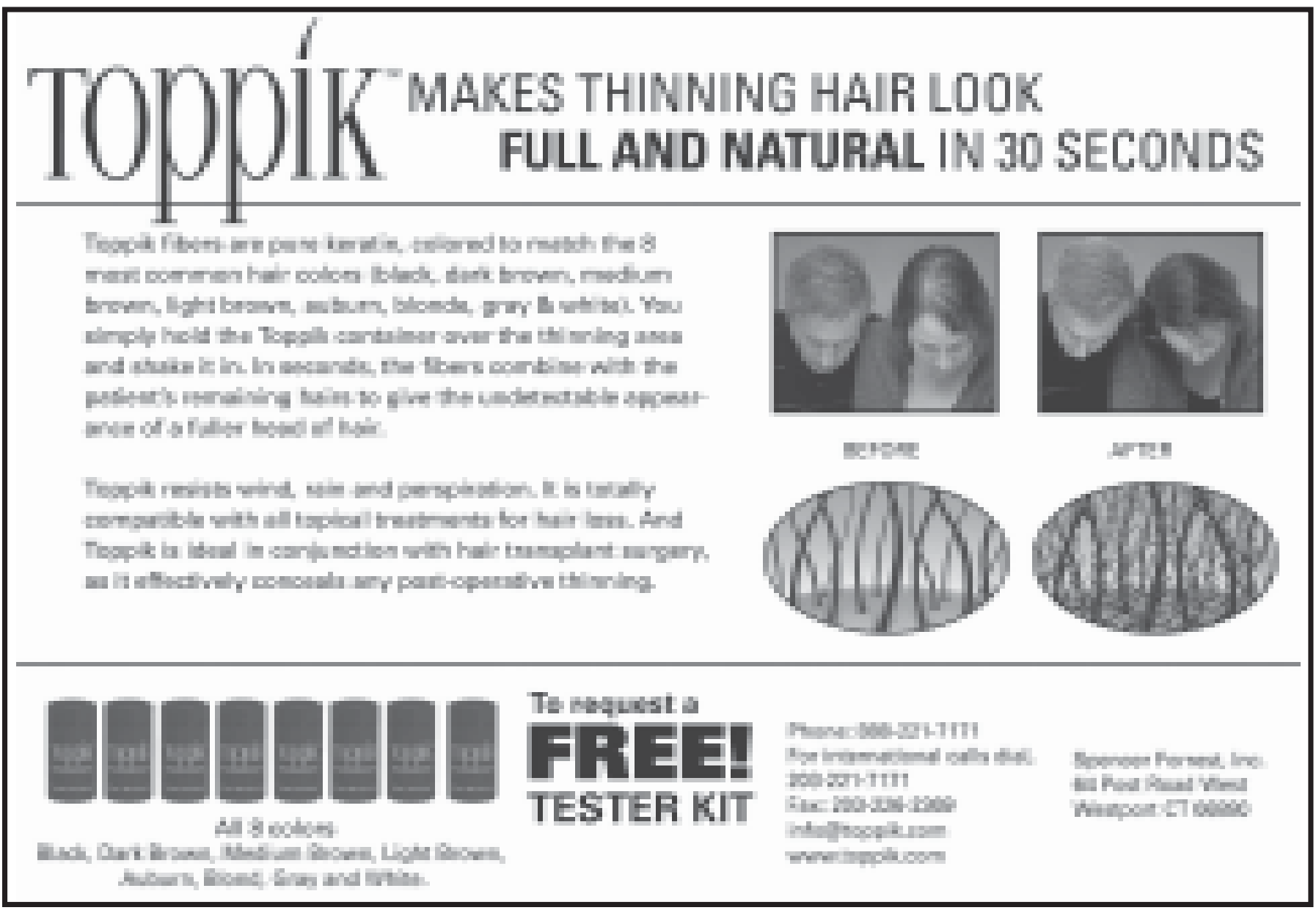

